\title{
Tissue distribution of autoantigen specific for primary sclerosing cholangitis
}

\author{
S K Lo, R W Chapman, K A Fleming
}

\begin{abstract}
Aim: To investigate the tissue distribution of the autoantigen specific for primary sclerosing cholangitis.

Methods: A range of normal frozen tissues including nervous system, muscle, uterus, ovary, prostate, pancreas, thyroid, salivary gland, adrenal gland, colon, gall bladder, stomach, jejunum, aorta, skin, kidney, liver, spleen and thymus was sectioned, fixed with acetone, and air-dried. Normal bone marrow and HL60, K562, and U937 cells were cytocentrifuged on to slides, air-dried, and alcohol fixed. Four sera from primary sclerosing cholangitis with high titre antibody ( $>1 / 100$ ) were used to screen the tissues using either two-step or APAAP immunohistochemistry. Normal sera were used as controls.

Results: Positive signal was detected in neutrophils in spleen with three out of four primary sclerosing cholangitis sera while one out of four primary sclerosing cholangitis sera stained spindle cells in the liver. All four sera stained mature neutrophils of the normal bone marrow. Some bone marrow neutrophil precursors (metamyelocytes and myelocytes) were also positive. All other tissues, including HL60, K562, and U937 cells, were negative. Normal sera were negative on all tissues.
\end{abstract}

Conclusion: Antigen specific for primary sclerosing cholangitis seems to be unique to neutrophil polymorphs and is present only after myeloblast differentiation of the myeloid cell line. The antigen may be within the secondary granule of the neutrophil polymorph.

(f Clin Pathol 1993;46:246-249)

Department of Gastroenterology, John Radcliffe Hospital, Oxford $S$ K Lo

R W Chapman

Nuffield Department of Pathology and Bacteriology,

University of Oxford

John Radcliffe

Hospital, Oxford

OX39DU

K A Fleming

Correspondence:

Dr K A Fleming

Accepted for publication

20 August 1992
Primary sclerosing cholangitis is a form of chronic cholestatic liver disease that causes inflammation and fibrosis of both the intraand extrahepatic bile ducts. The aetiology of this condition remains unknown. There is, however, a close association with HLA B8 DR3 and DR2 haplotype. ${ }^{1-3}$ This, coupled with many other humoral and cellular immune abnormalities, ${ }^{4-12}$ strongly favours an autoimmune basis for this disorder. A previous study from this unit has shown that a highly specific anti-neutrophil antibody is present in the serum of patients with primary sclerosing cholangitis. ${ }^{13}$ This antibody seems to differ from the anti-neutrophil antibody found in systemic vasculitis, glomerulonephritis, or Wegener's granulomatosis.

\section{Methods}

The project was approved by the Central Oxford Research Ethics Committee.

Sera were obtained from four patients with primary sclerosing cholangitis (three men, age range 57-67, mean 61 years). Primary sclerosing cholangitis was diagnosed on biochemical, histological, and cholangiographic criteria. ${ }^{14}$ All patients also had concomitant ulcerative colitis. Three patients were taking sulphasalazine and one had had a colectomy. All these patients had an anti-neutrophil serum antibody titres greater than or equal to $1 / 100$ as determined by an immunoalkaline phosphatase technique. ${ }^{13}$

Sera were also obtained from three normal subjects ( 2 men, age range $30-51$, mean 46 years).

All sera were stored at $-20^{\circ} \mathrm{C}$ and were thawed slowly at room temperature just before use. Repeated freezing and thawing were avoided.

A range of normal tissues including central nervous system (cerebrum, cerebellum, and spinal cord), muscle (skeletal, smooth, and heart), uterus, ovary, prostate, pancreas, thyroid, salivary gland, adrenal gland, colon, gall bladder, stomach, jejunum, aorta, skin, kidney, liver, spleen and thymus were studied. The tissues were either obtained within two hours of surgical resection or from necropsy within 12 hours of death. These were snap frozen and stored in liquid nitrogen.

Normal bone marrow (a gift from $\mathrm{Dr} T$ Littlewood, Oxford) was harvested during transplantation and anticoagulated in EDTA. This was then diluted 1 in 10 with $5 \%$ fetal calf serum (Tissue Culture Service) in TRISbuffered saline (TBS, $50 \mathrm{mM}$ TRIS (Sigma), $145 \mathrm{mM} \mathrm{NaCl}, \mathrm{pH} 7 \cdot 6$ ). Red blood cells were separated from white blood cells by sedimentation with JPM Prep (TechGen International, London). The white cells were aspirated from the medium and resuspended in the same $5 \%$ fetal calf serum. This single wash was enough to remove most of the JPrep medium. Cells were pelleted by centrifugation at $500 \times g$ and then resuspended again in $5 \%$ fetal calf serum. Aliquots of this were cytocentrifuged (Shandon Southern Cytocentrifuge, Cheshire) onto slides for $5 \mathrm{~min}$ utes at $500 \mathrm{rpm}$.

HL60 (promyelocytic leukaemic cell), K562 (erythroid leukaemic cell), and U937 


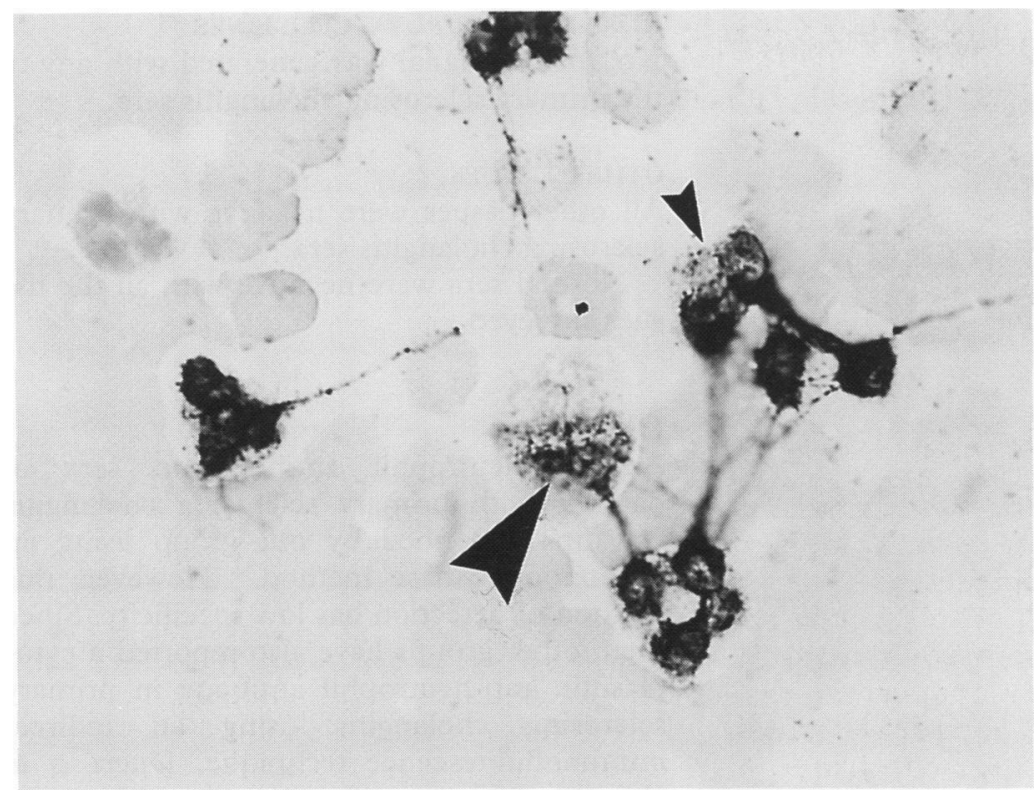

Figure 1 Both myelocyte (big arrow) and metamyelocyte (small arrow) give positive signal. The other positive cells are mature neutrophil polymorphs.

cells (histiocytic lymphoma cell) were also harvested, cytocentrifuged on to slides and treated as in the case of bone marrow. All cell lines were supplied by Dr D Y Mason, Oxford.

\section{Immunohistochemistry}

ALKALINE PHOSPHATASE ANTI-ALKALINE PHOSPHATASE (APAAP) TECHNIQUE ${ }^{15}$

All tissues, except bone marrow, were cryostat sectioned $(5 \mu \mathrm{M})$ at $-20^{\circ} \mathrm{C}$, mounted at room temperature on to silanised slides, and then air-dried. The sections were fixed with acetone for 10 minutes and again air-dried. Serum was diluted 1 in 10 in TBS and incubated with the section in a moist chamber for 30 minutes. The serum was then washed off with TBS, followed by incubation with a sec-

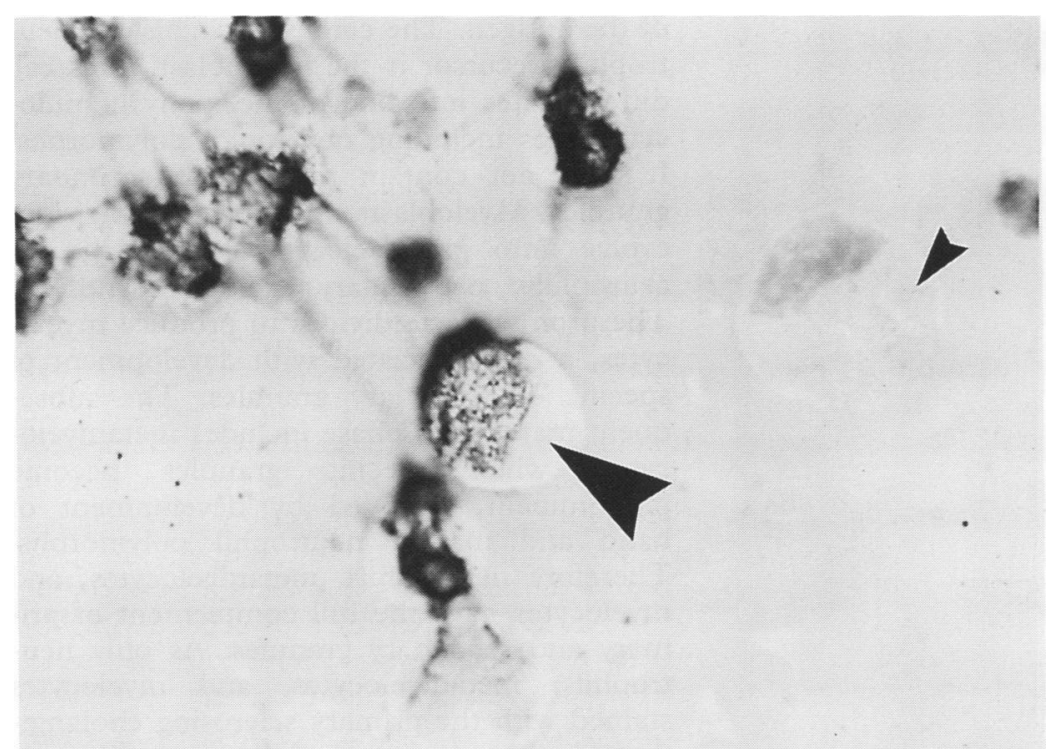

Figure 2 The myelocyte is again positive (large arrow). Note the negative staining promyelocyte (small arrow). ondary antibody, rabbit anti-human immunoglobulin heavy chain (Dako) conjugated to alkaline phosphatase, diluted 1 in 30 in TBS. The antibody was rinsed off with TBS after 30 minutes. Mouse anti-rabbit monoclonal antibody, MR12 (a gift from Dr D Y Mason, Oxford) was then incubated with the section for 30 minutes and washed in TBS. Rabbit anti-mouse antibody, Z259 (Dako, High Wycombe) diluted 1 in 50, was incubated with the section for a further 30 minutes. This was washed off and the APAAP complex (a gift from Dr D Y Mason), diluted 1 in 2 using TBS, was then added. Incubation time was again 30 minutes followed by washing in TBS.

The alkaline phosphatase substrate was prepared by dissolving $2 \mathrm{mg}$ of naphtol ASMX (Sigma) in $0.2 \mathrm{ml}$ of dimethylformamide (Sigma) and then adding $9.8 \mathrm{ml}$ of $0.1 \mathrm{M}$ TRIS buffer, $\mathrm{pH} 8 \cdot 2$. Immediately before this preparation was used, Fast Red TR salt (Sigma) was added at a concentration of 1 $\mathrm{mg} / \mathrm{ml}$ and the solution filtered directly on to the slide and incubated for a total of $12 \mathrm{~min}$ utes.

\section{Two-step immunoalkaline phosphatase technique}

Cytocentrifuged bone marrow cells were fixed with absolute alcohol for 5 minutes and then air-dried. The cells were then incubated with serum diluted 1 in 10 in TBS for 30 minutes in a moist chamber. This was washed off with TBS and a secondary antibody, rabbit against human immunoglobulin heavy chain conjugated with alkaline phosphatase, D342 (Dako), diluted 1 in 30 with TBS, was used to incubate with the cells for a final $30 \mathrm{~min}$ utes. Fast Red TR salt was again used to develop the reaction as described above.

The HL60 cells and other cell lines were treated similarly.

All slides were counterstained with haematoxylin after development with Fast Red TR salt.

All experiments were carried out at room temperature.

\section{Results}

\section{BONE MARROW}

Mature neutrophils were positively stained using four primary sclerosing cholangitis (PSC) sera. They demonstrated the granular cytoplasm with perinuclear accentuation and surrounding filaments characteristic of PSC. ${ }^{13}$ Some neutrophil precursors (metamyelocytes and myelocytes) were also positive (fig 1). However, earlier precursors including myeloblasts and promyelocytes were not stained. An unstained promyelocyte is shown on fig. 2. Other mononuclear cells, red blood cells, and their precursors as well as megakaryocytes were negative.

\section{SPLEEN}

Three out of the four sera stained cells surrounding the lymphoid areas of the spleen 


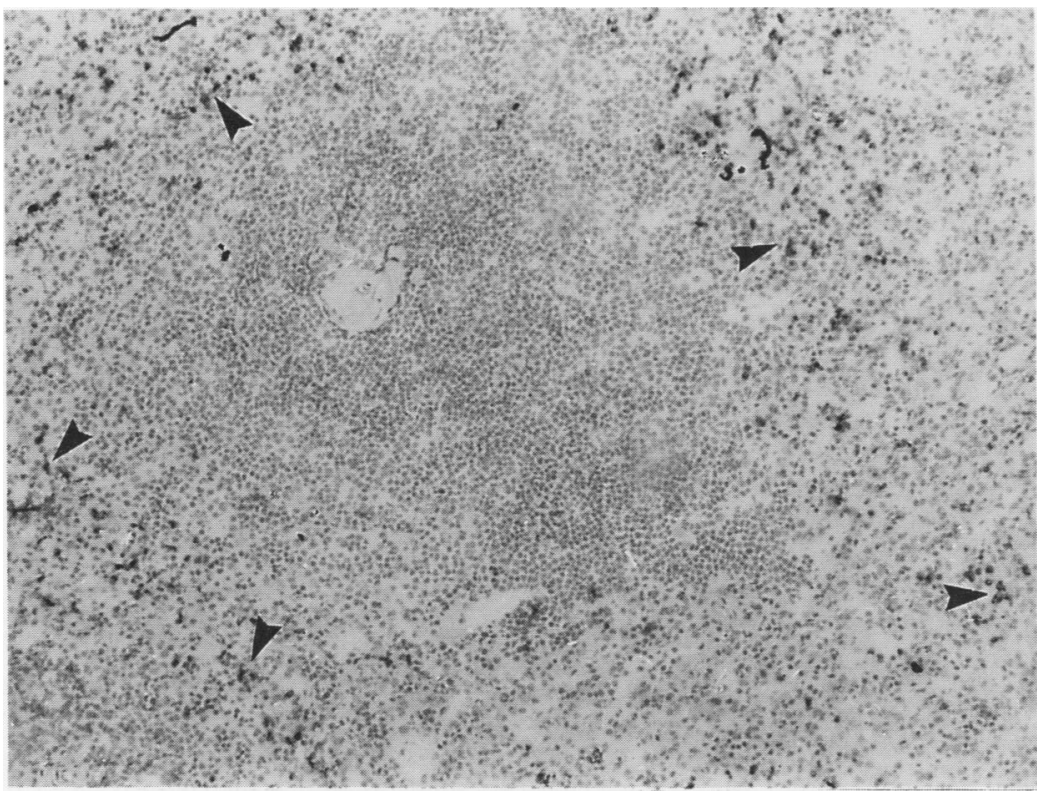

Figure 3 This is a section of the spleen with a central arteriole. Positively stained cells (arrowed) surround the lymphoid area in a circumferential manner.

circumferentially (fig 3). The nucleus of the stained cells demonstrated multilobes characteristic of neutrophils. Neutrophils are known to be present in splenic tissue. Granules were also seen in the cytoplasm. The centre of the lymphoid tissue did not stain.

LIVER

Sparse positive signal was detected in one out of four primary sclerosing cholangitis sera in the liver sections. The positive cells appeared to be sinusoidal cells (fig 4), although definite identification was impossible. Granules could be seen in the cytoplasm and there seemed to be some filaments around the cell. The nucleus was not visualised accurately but it did not appear to be multilobed. It is therefore unlikely that these cells were neutrophil polymorphs. Neither the hepatocytes nor the bile ducts were stained.

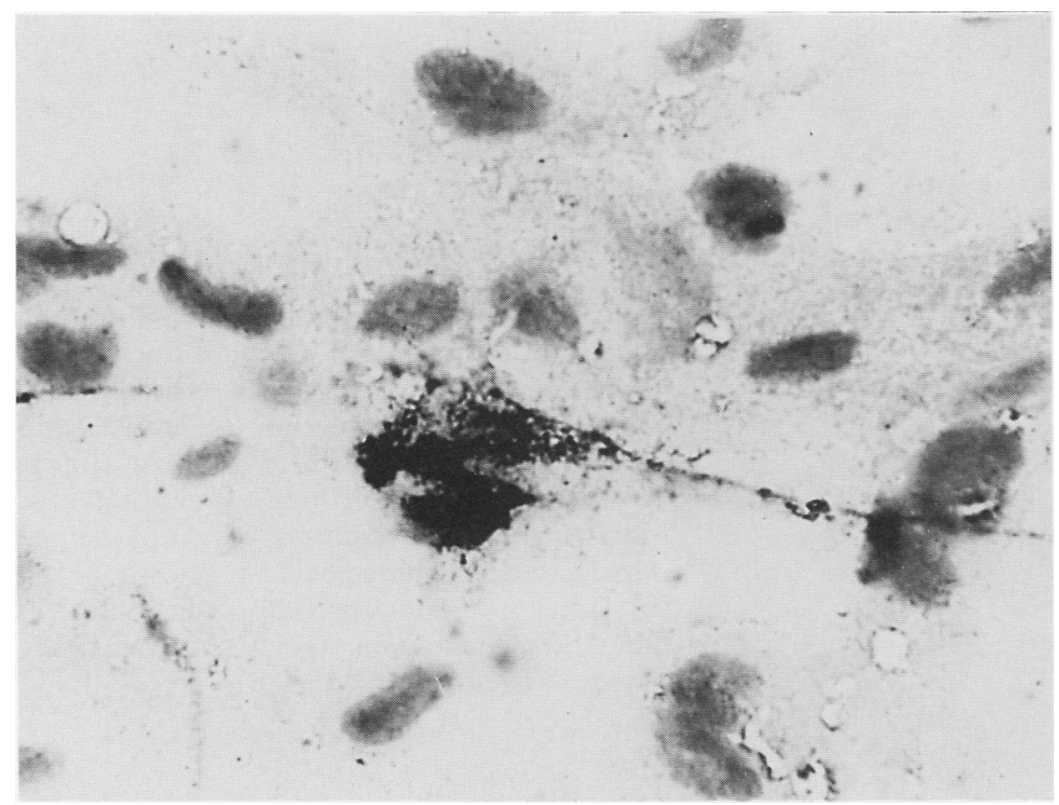

Figure 4 Section of the liver which shows a positively stained spindle-shaped cell.
HL60, K562, AND U937 CELL LINES

No positive signal was generated with any of the primary sclerosing cholangitis sera.

\section{OTHER TISSUES}

All other tissues were negative with primary sclerosing cholangitis sera.

Normal sera were negative with all the tissues surveyed.

\section{Discussion}

An anti-neutrophil antibody in sera of patients with primary sclerosing cholangitis was first described by our group using an immunoperoxidase method. ${ }^{16}$ However, this method of detection has low specificity. Since then, other groups have also reported a cytoplasmic anti-neutrophil antibody in primary sclerosing cholangitis using an indirect immunofluorescence technique. Duerr et al claimed high specificity using this technique. ${ }^{17}$ This has not been confirmed by others, ${ }^{18}$ including ourselves. ${ }^{13}$ Subsequently, we have reported a highly sensitive and specific method, detecting the cytoplasmic anti-neutrophil antibody using an immunoalkaline phosphatase technique. The specificity and sensitivity of this assay has been confirmed. ${ }^{19}$

Work has been in progress in several laboratories to identify the antigen. Using sodium dodecyl sulphate polyacrylamide gel electrophoresis on sonicated neutrophils, Klein et al reported the identification of a 60 kilodalton epitope which is claimed to be specific for primary sclerosing cholangitis serum. ${ }^{20}$ However, we have not been able to confirm this. ${ }^{13}$

The aim of this study was to investigate if any other tissues or cells express this antigen, partly as a better source of the antigen for extraction and analysis, and partly to obtain some insight into its nature and function. It seems that the only cells that carry this antigen are mature neutrophils and some of their immediate precursors. These results provide us with some clues as to the possible nature of the antigen. The earliest recognisable neutrophil precursor is the myeloblast. This cell differentiates into one of the many granulocytic lines including neutrophil polymorphs. It does not contain primary or secondary granules. Myeloblasts, following cell division, evolve into promyelocytes, the stage of azurophilic or primary granules synthesis. The promyelocyte divides to produce myelocytes, a cell associated with development of specific or secondary granules. The subsequent maturation phase includes metamyelocytes, when specific granules become predominant, followed by development of band and mature neutrophil polymorphs. Therefore neutrophils, metamyelocytes, and myelocytes have the full complement of primary and secondary granules. As only neutrophils, metamyelocytes, and myelocytes stained with the primary sclerosing cholangitis sera, this suggests that the antigen locates only within the secondary granule. This argument is reinforced by the finding that the 
HL60, a promyelocytic leukaemic cell line, was negative.

The antigen for cytoplasmic anti-neutrophil antibody in Wegener's granulomatosis has been identified as serine proteinase 3 (with a molecular weight of 29 kilodaltons) which is present in the primary granule. ${ }^{21} 22$ Many laboratories have shown that proteinase 3 is not the antigen to which the autoantibody in primary sclerosing cholangitis is reactive. ${ }^{1723}$ Myeloperoxidase, elastase, and cathepsin $G$, all of which are present in the primary granule, have also been excluded as a potential antigen in PSC. ${ }^{17} 23$

In conclusion, the PSC specific antigen is probably expressed exclusively by the neutrophil polymorph and its slightly earlier precursor. The antigen could be in the secondary granule. But the exact nature of the antigen remains to be determined.

We thank Dr T Littlewood for assessing the bone marrow slides and $\mathrm{Mr} \mathrm{J}$ Richardson for photographic assistance.

1 Chapman RW, Varghese Z, Gaul R, Patel G, Kokinon N, Sherlock S. Association of primary sclerosing cholangitis with HLA-B8. Gut 1983;24:38-41.

2 Schrumpf E, Fausa O, Forre O, Dobloug JH, Ritland S, Thorsby E. HLA antigens and immunoregulatory $T$ cells in ulcerative colitis associated with hepatobiliary disease Scand 7 Gastroenterol 1982;17:187-91.

3 Donaldson PT, Farrant JM, Wilkinson ML, Hayllar K, Portmann BC, Williams R. Dual association of HLA Portmann BC, Williams R. Dual association of HLA DR2 and DR3 with prim

4 Alberti-Flor JJ, de Medina M, Jeffers L, Schultz DR, Schiff ER. Elevated levels of immunoglobulins and immune complexes in the bile of patients with primary sclerosing cholangitis $A m$ f Gastroenterol 1986;81:325-8.

5 Bodenheimer HC Jr, LaRusso NF, Thayer WR Jr, Charland C, Staples PJ, Ludwig J. Elevated circulating immune complexes in prin

6 Lawley TJ, Hall RP, Fauci AS, Katz SI, Hamburger MI, Frank MM. Defective Fc-receptor functions associated with the HLA B8/DRw3 haplotype: Studies in patients with the HLA B8/DRw3 haplotype: Studies in patients with dermatitis herpetiformis
Engl $₹$ Med 1981;304:185-92.

7 Lindor KD, Wiesner RH, Katzmann JA, LaRusso NF, Beaver SJ. Lymphocyte subsets in primary sclerosing cholangitis Dig Dis Sci 1987;32:720-5.

8 McFarlane IG, Wojcicka BM, Tsantoulas DC, Portmann
BC, Eddleston AL, Williams R. Leukocyte migration inhibition in response to biliary antigens in primary biliary cirrhosis, sclerosing cholangitis and other chronic liver diseases Gastroenterology 1979;76:1333-40.

9 Minuk GY, Angus M, Brickman CM, et al. Abnormal clearance of immune complexes from the circulation of patients with primary sclerosing cholangitis patients with primary sciler
Gastroenterology $1985 ; 88: 166-70$.

10 Raeman F, De Cock W, De Beukelaar T, De Cree J, Verhaegen $H$. Enumeration of $T$ lymphocytes subsets in autoimmune disease using monoclonal antibodies Clin Exp Immunol 1981;45:475-9.

11 Snook JA, Chapman RW, Sachdev GK, et al. Periphera blood and portal tract lymphocyte populations in primary sclerosing cholangitis. F Hepatol 1989;9:36-41.

12 Whiteside TL, Lasky $\mathrm{S}, \mathrm{Si} \mathrm{L}$ Van Thiel $\mathrm{DH}$ Immunologic analysis of mononuclear cells in liver tissues and blood of patients with primary sclerosing cholangitis Hepatology 1985;5:468-74.

13 Lo SK, Fleming KA, Chapman RW. Prevalence of antineutrophil antibody in primary sclerosing cholangitis and ulcerative colitis using an ankaline phosphatase method Gut 1992; 33:1370-5.

14 Chapman RW, Arborgh BA, Rhodes JM, et al. Primary sclerosing cholangitis: a review of its clinical features, cholangiography, and hepatic histology. Gut 1980; 21:870-7.

15 Cordell J, Falini B, Erber WN, et al. Immunoenzymatic labelling of monoclonal antibodies using immune complexes of alkaline phosphatase and monoclonal antialkaline phosphatase (APAAP complexes) $\exists$ Histochem Cytochem 1984;32:219-29.

16 Snook JA, Chapman RW, Fleming K, Jewell DP. Antineutrophil nuclear antibody in ulcerative colitis, neutrophil nuclear antibody in ulcerative colitis, Crohn's disease and primary

17 Duerr RH, Targan SR, Landers CJ, et al. Neutrophil cytoplasmic antibodies: A link between primary sclerosing cholangitis and ulcerative colitis. Gastroenterology 1991;100:1385-91.

18 Sharma AN, Rabson AR, Kaplan MM. Perinuclear antineutrophil cytoplasmic antibodies in primary sclerosing cholangitis. Hepatology 1991;14:64A.

19 Lo SK, Chapman RWG, Chessman P, et al. Anti-neutrophil antibody-A test for autoimmune primary sclerosing cholangitis in childhood? Gut (in press)

20 Klein R, Eisenburg J, Weber P, Seibold F, Berg PA Significance and specificity of antibodies to neutrophils detected by Western blotting for the serological diagnosis of primary sclerosing cholangitis. Hepatology 1991; 14:1147-52.

21 Goldschmeding $R$, van der Schoot CE, ten Bokkel Huinink $\mathrm{D}$, et al. Wegener's granulomatosis autoantibodies identify a novel diisopropylfluorophosphatebinding protein in the lysosomes of normal human neutrophils $\mathcal{f}$ Clin Invest 1989;84:1577-87.

22 Niles JL, McCluskey RT, Ahmad MF, Arnaout MA Wegener's granulomatosis autoantigen is a novel neutrophil serine proteinase Blood 1989;74:1888-93.

23 Shanahan $F$, Landers $C$, Duerr $R$, Targan $S$. Neutrophil autoantibodies as disease markers for ulcerative colitis Immunol Res 1991;10:479-84. 